\title{
Öğrencilerin Kodlamaya Yönelik Tutumları: Bir Ölçek Geliştirme Çalışması
}

\author{
DOI: 10.26466/opus.802939
}

\author{
* \\ Mustafa Serkan Abdüsselam* - Mustafa Uzoğlu ** \\ * Dr.Öğr.Üye., Giresun Üniversite, Eğitim Fakültesi, Giresun/Türkiye \\ E-Posta: mustafa.serkan@giresun.edu.tr \\ ORCID: 0000-0002-3253-7932 \\ ** Prof.Dr., Giresun Üniversite, Eğitim Fakültesi, Giresun/Türkiye \\ E-Posta: mustafa.uzoglu@giresun.edu.tr \\ ORCID: $\underline{0000-0002-4346-5161}$
}

\section{Öz}

Bu çalışmanın amacl, ortaokul öğrencilerinin kodlamaya ilişkin tutumların ölçen geçerli ve güvenilir bir ölçme aracı geliştirmektir. Ölçme aracının maddeleri ile ilgili literatür taramasının ardından, on öğrenciye kodlamanın ne olduğu hakkında 1 adet açık uçlu soru sorulmuştur. Elde edilen verilerden yararlanılarak 55 maddelik beşli likert tipi madde havuzu oluşturulmuştur. Kapsam geçerliği sonucunda 53 maddeye düşürülen taslak ölçek toplam 8 okuldan 675 ortaokul 5., 6., 7. ve 8. sinnf öğrencilerine uygulanmıştır. Geliştirilen ölçeğin KMO değeri .96 ve Bartlett's testi değeri ise $x 2=8970,78$; $s d=1378(p<.01)$ olarak tespit edilmiştir. Ölçeğin maddelerinin faktör yük değerlerinin .510 ile .831 şeklinde bir stralamaya sahip olduğu belirlenmiştir. Madde analizinde, tek faktörlü ölçekte yer alan 47 maddenin madde-toplam korelasyon katsayılarmın 60 ile .76 arasında değiş̧tiği, üst \%27 ve alt \%27 ortalama puanlar arasındaki farkların anlamlı olduğu görülmüştür. Ölçeğin Cronbach Alfa güvenirlik katsayısı ise .93 olarak bulunmuştur. Faktör analizleri sonucunda 47 ölçek maddesinin bir faktörde toplandığı ve ölçeğin toplam varyansının \%56.75'ini açıkladığı belirlenmiştir. Doğrulayıcı faktör analizinin uyum indekslerine bakıldığında ölçeğin tek faktörlü kabul edilebilir uyum düzeyine sahip olduğu bulunmuştur. Bu araştırmada geliştirilen kodlama tutum ölçeğinin yapılacak araştırmalara katkı sağlayacağı düşünülmektedir.

Anahtar Kelimeler: Kodlama, kodlamaya ilişkin tutum, ortaokul öğrencileri, tutum, ölçek geliştirme. 


\title{
Students' Attitudes Towards Coding: A Study of Scale Development
}

\begin{abstract}
The aim of this study is to develop a valid and reliable measurement tool that measures the attitudes of secondary school students towards coding. The literature related to the items of the measurement tool was scanned, and one open-ended question was asked about what coding means to the ten students about the coding. By using the data obtained, 5-point Likert-type pool with 55 items was created. Factor load values of the items of the scale showed a distribution between .510 and .831 . As a result of the content validity, the draft scale which was reduced to 53 items was applied to the 5 th, 6 th, 7 th and 8 th grade students in 675 secondary schools from a total of 8 schools. The KMO value of the developed scale is ,96 and the Bartlett's test value is $x 2=8970.78 ; s d=1378(p<, 01)$. In item analysis, item-total correlation coefficients of 47 items in single-factor scale ranged from .60 to .76 , with differences between the average scores of the upper $27 \%$ and the lower $27 \%$. The Cronbach Alpha reliability coefficient of the scale was found to be .93. As a result of factor analysis, it was determined that 47 items were collected in one factor and explained $56.75 \%$ of the total variance of the scale. According to the confirmatory factor analysis, when the fit indices were examined, it was found that the single factor structure of the scale had an acceptable compliance level. It is thought that the coding attitude scale developed in this study will contribute to the researches.
\end{abstract}

Keywords: Coding, attitude towards coding, middle school students, Attitude, scale development 


\section{Giriş}

Çağımızda bilişim teknolojilerinin eğitim alanında daha fazla rol almasıyla günümüz öğrencilerinin bilgisayar okuryazarı olmaları beklenilmektedir (Sayın ve Seferoğlu, 2016). Öğretim süreçlerinde bilişim teknolojisi araçlarının kullanılması ve öğrencilerin kendi ürünlerini bu teknolojileri kullanarak üretebilmeleri (Demirer ve Sak, 2015), meraklı ve istekli öğrencileri bilgisayar sistemlerinin nasıl çalıştığını anlamaya yönlendirmiştir (Sayın ve Seferoğlu, 2016). Böylece öğrenciler 21.yy. becerileri kazanırken, ileride karşılaşacakları problemlerin üstesinden gelebilecekleri yeni firsatlar elde edebileceklerdir (Demirer ve Nurcan, 2016). Bilişim öğretimi içerisinde programlama öğretiminin, öğrencilerin birçok becerisine katkı sağladığı bilinmektedir (Begosso ve da Silva, 2013). Programlama, özellikle öğrencilerin mantıksal düşünme ve problem çözme becerilerini geliştirmektedir (Sayın ve Seferoğlu, 2016). Bu nedenle birçok ülke 21.yy. becerilerinden olan bilgi-işlemsel düşünme becerisi kazandırmak adına müfredatlarını güncellemekte ve eğitim-öğretim ortamlarına programlama ve kodlama öğretimini dâhil etmektedir (Demir ve Seferoğlu, 2017; Lye ve Koh, 2014; Yağcl, 2018). Ülkelerden bazıları müfredatlarında "programlama" başlığını kullanırken; bazıları ise "bilgi-işlemsel düşünme", "algoritma", "kodlama" ya da "robotik" başlıkları kullanmaktadır (Balanskat ve Engelhardt, 2014). Müfredatlardaki başlıklar değişse de içerikte bilgi-işlemsel düşünme akademik bir beceri olarak kazandırılmasının hedeflendiği görülmüştür (Sayın ve Seferoğlu, 2016). Öğrencilerin bilgi-işlemsel becerilerini geliştirmek amacıyla çeşitli programlama ve kodlama etkinlikleri, STEM etkinliklerinin de içine yerleştirilmiş (Taccle, 2019), böylece tüm öğretim süreci mühendislik teması altında robotik çalışmalarla da uygulamalı hale dönüştürülmüştür (Eguchi, 2014).

Ülkelerin kabul ettikleri müfredatlarında kullandıkları isimler farklılaşsa da temelde öğrencilerin mantıksal düşünme, problem çözme ve kodlama becerilerini destekleyen bir öğrenme alanı oluşturulmaya odaklanılmış (Sayın ve Seferoğlu, 2016) böylece öğrencinin bilgi-işlemsel düşünme becerilerine katkı sağlanması amaçlanmıştır (Demir ve Seferoğlu, 2017; Yağcı, 2018). Günümüzde okul uygulamaları yanında, akademik alanda da bilgi-işlemsel düşünme becerilerine odaklandığı görülmektedir. Araştırmalar kapsamında bilgi-işlemsel düşünme, analitik düşünme, mantıksal düşünme, program- 
lama ve akademik başarı arasında pozitif ilişkiler olduğunu gösteren akademik çalışmalar söz konusudur (Baratè, Ludovico ve Mangione, 2016; Sebetci ve Aksu, 2014; Yünkül, Durak, Çankaya ve Misırlı, 2017). Yine blok tabanlı kodlama uygulamalarının problem çözme (Begosso ve da Silva, 2013), mantıksal ve matematiksel düşünmeyi geliştirme (Taylor, Harlow ve Forret, 2010) üzerinde olumlu etkisi olduğunu gösteren araştırma bulguları bulunmaktadır. Bir grup araştırmacı da (Barendsen ve ark. 2015; Brown, Mongan, Kusic, Garbarine, Fromm ve Fontecchio, 2008). programlama öğrenimi ile problem çözme becerisinin birbirileri üzerine etkilerini incelemiştir

Program ve kodlama, öğrenci dünyasına yeni giren kavramlar olmasa da, teknolojideki yeniliklerle birlikte bu kavramların anlamları genişlemiştir. Öğrenci açısından bakıldığında program öğrencinin yapacağı etkinlikleri düzenleyen, günlük olarak izlemesi gereken adımları listeleyen bir yönerge olarak düşünülebilir. Fakat bilgisayar dilinde program, tespit edilen problemin çözümüne yönelik geliştirilmiş algoritmayla öngörülen adımları izleyen işlemciyi eyleme geçiren yapının tümünü kapsamaktadır (Yaşar, 2014). Oluşturulan yapı programlama olarak tanımlanabilir.

Öğrenciler kodlamayı, sınav esnasında, sınav sorularına verdikleri yanıtları cevap kâğıdına işaretleme eylemi olarak ifade etmektedirler. Bilgisayar dilinde ise kodlama, bir problemin çözümüne yönelik tasarlanan adımlar (öngörülen algoritma) çerçevesinde, söz konusu programlama diline özgü olarak kullanılan kod bloklarını ya da kod metinlerini ifade etmektedir (Yükseltürk ve Üçgel, 2018). Dolayısıyla programlama, kodlamayı da kapsayan çeşitli bilişsel beceriler gerektirmektedir (Lye ve Koh, 2014). Programın oluşturabilmesi için kodlama gerçekleştirilmelidir. Bu süreci kolaylaştırmak ve basitleştirmek adına önce programın algoritmasının kurulması gereklidir. Şekil 1'de program oluşturma süreci görselleştirilmiştir.

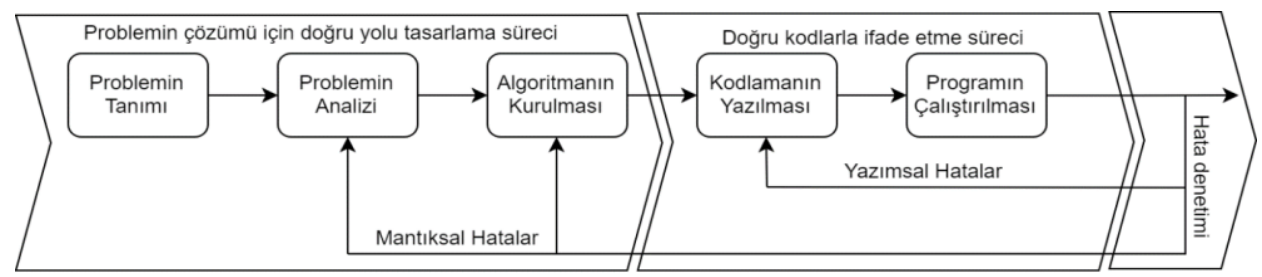

Şekil 1. Program oluşturma süreci. 
Programlama öğretiminin tarihçesi incelendiğinde, 1960'll yıllarda Logo programlama dili ile kullanıma başlandığı görülmektedir. Günden güne programlama öğrenmeye olan ilginin artması, code.org gibi organizasyonların düzenlenmesine ve Scratch gibi programlama araçlarının hızla yaygınlaşmasina neden olmuştur (Moreno-León, Robles ve Román-González, 2015). Türkiye'de 2012 yılından itibaren bu içerikler ortaokullarda Bilişim Teknolojileri ve Yazılım dersi ile öğretilmeye başlanmıştır. Blok kodlamayı temel alan Scratch'ın sağladığı kolay arayüzle kodlama yapma kolaylaştırılmıştır. Kodlamanın kolaylaşması öğrencilerin derse olan ilgisini ve motivasyonlarını arttığından (Howland ve Good, 2015) ortaokullarda bu ders kapsamında Scratch kullanımı yaygınlaşmıştır (Brennan ve Resnick, 2013; Çatlak, Tekdal ve Baz, 2015). Güncel araştırmalar blok tabanlı kodlama ve STEM eğitimi kapsamında öğretmenlerin de kodlama ve programlamayla iligli bilgi sahibi olmaları, hatta hâkim olmaları gerektiğini göstermektedir (Guenaga, Menchaca, Garaizar ve Eguíluz, 2017; Love, Winter, Corritore ve Faimon, 2016).

Özetle programlamanın daha özelde kodlama öğretiminde, blok kodlamayı temel alan yazılımların kullanılmasının avantaj sağladığı, ögretimi kolaylaştırdığı, dolaylı olarak öğrencilerin farklı düşünme becerileri geliştirmeleri üzerinde olumlu etkisinin olduğu söylenebilir. Bu etkide, öğrencilerin kodlamaya karşı görüşleri, sevip sevmemeleri, daha genel bir ifade ile tutumları önem teşkil etmektedir. Öğrenci tutumları, uygulamada ne yapacakları hakkında fikir edinilmesinde, öğrenme süreci ve sonrasında elde edecekleri kazanımlardan fiziksel ve zihinsel olarak nasıl etkilenecekleri, kodlama başarı durumlarının yordanmasına rehberlik edeceğinden önemlidir (Fritz, 2008). Öğrenme konusu ya da durumuna ilişkin tutumun öğrencinin performansını etkilediği bilindiğinden (Kind, Jones ve Barmby, 2007) Bilişim Teknolojileri ve Yazılım dersi içeriğinde yer alan blok kodlamaya ilişkin öğrencilerin tutumlarının belirlenmesinin önemli olduğu, bu nedenle kodlama tutum ölçeğinin geliştirilmesi zaruri görülmüştür. Konuyla ilişkili son zamanlarda eğitsel bilgisayar oyunlarına yönelik ölçek geliştirilmiş olsa da (Keçeci, Alan ve Zengin, 2016), kodlama becerilerinin özellikle STEM eğitiminde önemli olduğu da göz önünde bulundurularak öğrencilerin kodlamaya ilişkin tutumlarını ölçen bir araca ihtiyaç duyulduğu öngörülmüştür. Bu çalışmada, bu ihtiyacın karşılanması ve alan yazındaki bu eksikliğin giderilmesine katkı sağlamak amacıyla kodlamaya karşı tutum ölçeğinin geliştirilmesi hedeflenmiştir. 
$\mathrm{Bu}$ araştırmanın amacı, ortaokul öğrencilerinin kodlamaya karşı tutumlarını ölçebilecek geçerli ve güvenilir bir kodlama tutum ölçeği geliştirmektir.

\section{Yöntem}

\section{Araştırmanın Modeli}

Bu tarama çalışmasında ortaokul öğrencilerinin kodlamaya karşı tutumlarını geçerli ve güvenilir bir şekilde ortaya koyabilecek tutum ölçeği geliştirmek amaçlanmıştır. Çalışmada, tutum ölçekleri içerisinde yaygın olarak kullanılan Likert tipi tutum ölçeği modeli benimsenmiştir. Likert tipi tutum ölçeği ölçekler içerisinde en yaygın olarak kullanılanıdır. Bu ölçek tipinde bireylerin verilen ifadelere katılıp katılmama durumu sorgulanmaktadır (Karagöz, 2017).

\section{Örneklem}

Kodlamaya karşı tutum ölçeği, bilişim teknolojileri ve bilgisayar dersi kapsaminda kodlama eğitimi alan ortaokul 5, 6, 7 ve 8. sınıf öğrencileri için geliştirilmiştir. Ortaokul düzeyinde farklı sınıflardan toplam 675 öğrenci araştırmaya veri sağlamıştır. Katılımcıların belirlenmesinde tabakalı amaçsal örnekleme yöntemi tercih edilmiştir. Bu yöntemde araştırmacılar, ihtiyaç duyulan veriye ulaşabileceklerini düşündükleri örneklemle çalışırlar (Fraenkel ve Wallen, 2003). İncelenen çalışmalarda amaçsal örneklemenin tercih edildiği araştırmaların rastgele seçim yoluyla gerçekleştirilen örneklemlerden ulaşılan veriler kadar verimli neticeler ortaya koyduğunu göstermektedir (Seale, Gobo, Gubrium ve Silverman, 2007).

\section{Verilerin Toplanması}

2018-2019 eğitim-öğretim yılında gerçekleştirilen bu çalışmada, ölçek geliştirme sürecinde veriler iki aşamada toplanmıştır. Birinci aşamada 5, 6, 7 ve 8 . Sınıflarda öğrenimleri süren 338 öğrenciden toplanan veriler (çalışma grubu 1) ölçeğin faktör yapısının tespitinde, 337 öğrenciden (çalışma grubu 2) ikinci turda toplanan veriler ise elde edilen faktör yapısının doğrulatılmasında kullanılmıştır. Hem açımlayııı hem de doğrulayıcı faktör analizlerinde kullanılan gruplara ait betimseller Tablo 1 ve 2' de sunulmuştur. 
Tablo 1. Çalışma grubu 1'in sınıflara göre dağılımı

\begin{tabular}{llllll}
\hline Sinıf Düzeyi & 5 & 6 & 7 & 8 & Toplam \\
\hline Öğrenci sayısı & 90 & 111 & 75 & 62 & 338 \\
\hline Yüzde & 27 & 33 & 22 & 18 & 100 \\
\hline
\end{tabular}

Tablo 1, 5. siniftan 90 (\%27), 6. siniftan 111 (\%33), 7 . siniftan 75 (\%22) ve 8. sinuftan 62 (\%18) olmak üzere toplam 338 kişinin bulunduğunu göstermektedir. 338 öğrencinin 163'ü erkek, 175'ise bayanlardan oluşmaktadır.

Çalışma grubu 2'yi oluşturan öğrenci sayısı 5, 6, 7 ve 8. sınıflardan meydana gelen 337 kişiden oluşmaktadır. Çalışma grubu 2, çalışma grubu 1'den elde edilen kodlamaya karşı tutum ölçeğinin faktör yapısının onaylanıp onaylanmadığını göstermek için kullanılmıştır. Bunun için çalışma grubu 1 öğrencilerinden kodlama tutum ölçeğinden elde edilen veriler üzerine doğrulayıcı faktör analizi uygulanmıştır. Tablo 2 çalışma grubu 2'yi oluşturan öğrencilerin sınıflara göre dağılımının frekans ve yüzdesini göstermektedir.

Tablo 2. Çalışma grubu 2'nin sımıflara göre dağılımı

\begin{tabular}{llllll}
\hline Sinıf Düzeyi & 5 & 6 & 7 & 8 & Toplam \\
\hline Öğrenci sayısı & 89 & 112 & 74 & 62 & 337 \\
\hline Yüzde & 27 & 33 & 22 & 18 & 100 \\
\hline
\end{tabular}

Tablo 2, 5. sinifdan 89 (\%27), 6. sinıfdan 112 (\%33), 7. sinıfdan 74 (\%22) ve 8. sinıfdan 62 (\%18) olmak üzere toplam 337 kişinin bulunduğunu göstermektedir. 337 öğrencinin 168'i erkek, 169'u ise bayanlardan oluşmaktadır.

\section{Veri Toplama Aracı ve Geliştirilmesi}

Literatür incelendiğinde ölçek geliştirme sürecinin birbirini takip eden aşamalardan meydana geldiği görülmektedir. Genellikle ölçme araçlarının geliştirilmesinde izlenen yolun aşağıdaki gibi olacağı görülecektir (Balcı, 2010; Bozdoğan, 2014, 2016; Bozdoğan ve Öztürk, 2008; Bozdoğan ve Uzoğlu, 2012; Karasar, 2012; Şeker ve Gençdoğan, 2006; Tyler, 1971; Yurdugül, 2005).

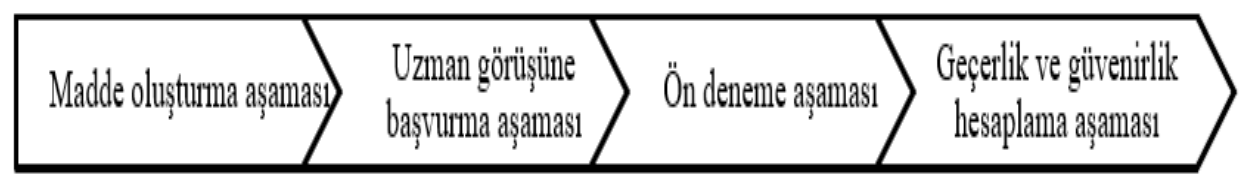

Şekil 2. Ölçme araçlarının geliştirilmesinde izlenen yollar. 
Madde oluşturma aşamasında ölçeğin nasıl hazırlanması gerektiği ile ilgili önceden yapılan çalışmalarda kullanılan ölçme araçları incelenmiş, eş zamanlı olarak bilgisayar dersi kapsamında kodlama eğitimi alan 5, 6, 7 ve 8 . sınıf öğrencilerinden kodlamanın ne olduğuyla ilgili açık uçlu sorular ile veri toplanmıştır. Öğrencilerin açık uçlu sorulara verdikleri cevaplar ve literatür dikkate alınarak 55 sorudan oluşan taslak ölçek araştırmacılar tarafındna geliştirilmiştir. Maddeler hazırlanırken: Maddelerin mümkün olduğunca eşit sayıda pozitif ve negatif ifade içermesine, basit ve anlaşılır olmasına, maddelerin çok fazla yargı/düşünce/duyuş içermemesine özen gösterilmiştir.

Geliştirilen taslak ölçeğin kapsam geçerliğini sağlamak için uzman görüşüne başvurulmuştur. Yapılan çalışmada iki bilgisayar öğretmeni, iki bilgisayar öğretmenliğinde görev yapan öğretim üyesi, bir fen eğitimcisi ile bir eğitim bilimci öğretim üyesinin düşüncelerine başvurulmuştur. Bu uzmanlar ölçek maddelerinin kodlamaya karşı tutumu ölçüp ölçmediği ve dil kurallarına uygunluğunu incelemişlerdir. Uzman görüşleri doğrultusunda toplam 55 maddeden oluşan madde havuzundan 53 maddenin uygunluğu tespit edilmiş; uzmanlar bazı maddeler üzerinde düzeltmeler yapılmışlardır. Böylece hazırlanan ölçme aracının kapsam geçerliği oluşturulmak istenmiştir.

Ön deneme aşamasında kodlamayla ilgili hazırlanan taslak, ortaokul öğrencilerinden oluşan 20 kişilik gruba uygulanmıştır. Öğrencilerin ölçeği cevaplama süresi belirlenmiş, ölçek maddelerinin anlaşılırlığı kontrol edilerek eksikliklerin olup olmadığı incelenmiş ve ölçek üzerinde gerekli düzeltmeler yapılmıştır. Ön deneme de 31 pozitif ve 22 negatif maddeden meydana gelen toplam 53 madde beşli Likert tipinde hazırlanmış ve maddelerin dereceleri; 1 "Hiç Katılmıyorum", 2 "Katılmıyorum", 3 "Kararsızım", 4 "Katılıyorum" ve 5 "Tamamen Katıllyorum" şeklinde kategorize edilmiştir. Adayların verdiği cevaplar puanlanırken, negatif maddelere verilen yanıtlar ters çevrilmiştir. Geliştirilen taslak ölçek Ocak 2018' de Giresun İl merkezinde amaçlı tabakalı örnekleme yöntemi kullanılarak tespit edilen 8 ortaokulun 5, 6, 7 ve 8 . sınıf öğrencilerine uygulanmıştır.

\section{Verilerin Analizi}

Kodlama tutum ölçeği kullanılarak öğrencilerden elde edilen veriler SPSS 23 ve AMOS 22 programları kullanılarak analiz edilmiştir. Kodlama tutum ölçeğinden elde edilen verilerin faktör analizine uygunluğu KMO testi ile test 
edilmiş ve daha sonra uygun olduğu belirlenince faktör analizi yapılarak ölçeğin yapısı belirlenmeye çalışılmıştır. Ölçeğin faktör sayısını ortaya çıkarmak maksadıyla, faktör analizi tekniklerinden döndürülmemiş ve asal eksenlere göre döndürülmüş (varimax rotated) temel bileşenler analizlerinden faydalanılmıştır. Ölçeğin yapı geçerliğinin belirlenmesinde açımlayıcı faktör analizi kullanılarak ölçeği oluşturan maddeler belirlenirken madde öz değer yükünün 1 ve değerinin en az .30 olması önemlidir (Büyüköztürk, 2005). Ölçeğin iç tutarlılık kat sayısı olan Cronbach Alpha' ya bakılarak güvenirlik saptanmaya çalışılmıştır. Kodlama tutum ölçeğindeki maddelerin ayırt etme derecelerini ortaya çıkarmak için madde-toplam test korelâsyonları hesaplanmış ve ölçek faktörlerinin ortaya çıkarılmasında da faktör özdeğer hesaplamaları gerçekleştirilmiştir. Açımlayıcı faktör analizi ile belirlenen yapının doğruluğu AMOS 22 paket programı kullanılarak doğrulayıcı faktör analizi ile model uyumuna bakılmıştır.

\section{Bulgular}

Araştırma kapsamında geliştirilen ölçeğin güvenirlik ve geçerlilik hesaplamaları bu bölümde sunulmuştur.

\section{Güvenirlik Hesaplama Aşaması}

Ölçek geliştirmede öncelikle güvenirlik incelenir daha sonra geçerlilik çalışması yapılır. Bunun nedeni güvenilir olan ölçek geçerli olabilir anlayışına dayanmaktadır (Bindak, 2005). Ölçeğin iç tutarlılığını saptamak için alt-üst grup ortalamaları farkına ve korelasyonu incelenir.

Alt-Üst Grup Ortalamaları Farkına Dayalı Madde Analizi: Ölçekteki maddelerin ayırt edicilikleri saptanırken, maddeler birer birer temel alınarak üst grup ve alt grup ölçek puanlarının ortalamalarındaki farkın anlamlılı̆̆ıyla ilgili $t$ değerine bakılmıştır. Bu bağlamda tutum puanlarının toplamı en büyükten en küçüğe doğru sıraya konulmuştur. Alt ve üst gruplar tüm ölçeğin \%27'sini içeren 91'er adaydan meydana gelmiştir. Aşağıdaki Tablo 3 ölçeğin alt $\% 27$ ve üst $\% 27^{\prime}$ lik grupların madde ortalamaları için t-testi sonuçlarını göstermektedir. 
Tablo 3. Ölçeğin Alt \% 27 ve Üst \%27' lik Gruplarn Madde Ortalamalan İçin t-Testi Sonuçlarn

\begin{tabular}{|c|c|c|c|c|c|c|c|c|c|c|c|}
\hline No & Grup & $\mathbf{N}$ & $\bar{x}$ & $t$ & $\mathrm{p}$ & No & Grup & $\mathbf{N}$ & $\bar{x}$ & $t$ & $\mathrm{p}$ \\
\hline \multirow{2}{*}{ M1 } & Üst & 91 & 2,34 & \multirow{2}{*}{$-17,183$} & \multirow{2}{*}{,000 } & \multirow{2}{*}{ M28 } & Üst & 91 & 2,60 & \multirow[t]{2}{*}{$-15,909$} & \multirow{2}{*}{, 000} \\
\hline & Alt & 91 & 4,67 & & & & Alt & 91 & 4,78 & & \\
\hline \multirow{2}{*}{ M2 } & Üst & 91 & 2,38 & \multirow{2}{*}{$-16,824$} & \multirow{2}{*}{,000 } & \multirow{2}{*}{ M29 } & Üst & 91 & 2,69 & \multirow{2}{*}{$-12,216$} & \multirow{2}{*}{, 000} \\
\hline & Alt & 91 & 4,65 & & & & Alt & 91 & 4,62 & & \\
\hline \multirow{2}{*}{ M3 } & Üst & 91 & 2,24 & \multirow{2}{*}{$-15,017$} & \multirow[t]{2}{*}{,000 } & \multirow{2}{*}{ М30 } & Üst & 91 & 2,70 & 15307 &, 000 \\
\hline & Alt & 91 & 4,47 & & & & Alt & 91 & 4,86 & $-15,30 /$ & \\
\hline$M$ & Üst & 91 & 2,99 & 11584 & 000 & 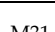 & Üst & 91 & 2,79 & 15094 & 000 \\
\hline 1014 & Alt & 91 & 4,78 & $-11,584$ & , 000 & 1)131 & Alt & 91 & 4,88 & $-15,094$ & ,000 \\
\hline 45 & Üst & 91 & 2,62 & 12097 & 000 & MT2 & Üst & 91 & 2,69 & 12701 & $0 \cap 0$ \\
\hline 105 & Alt & 91 & 4,63 & $-12,991$ & , 000 & $\mathrm{M} 132$ & Alt & 91 & 4,73 & $-15,191$ & ,000 \\
\hline$M 6$ & Üst & 91 & 2,83 & $-12,727$ & ( & 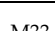 & Üst & 91 & 2,47 & 16116 & 000 \\
\hline 196 & Alt & 91 & 4,74 & & ,000 & M33 & Alt & 91 & 4,79 & $-16,116$ & , 000 \\
\hline M7 & Üst & 91 & 2,73 & 8285 & 000 & $M 34$ & Üst & 91 & 2,70 & 11058 & 000 \\
\hline D1/ & Alt & 91 & 4,18 & $-8,280$ & , 000 & V134 & Alt & 91 & 4,54 & $-11,030$ &, 000 \\
\hline$M 8$ & Üst & 91 & 2,51 & -11663 & 000 & M35 & Üst & 91 & 2,86 & $-14,389$ & 000 \\
\hline 1018 & Alt & 91 & 4,46 & $-11,000$ &, 000 & 10130 & Alt & 91 & 4,85 & & ,000 \\
\hline$M O$ & Üst & 91 & 3,02 & 8007 & ( & 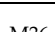 & Üst & 91 & 2,57 & $-12,629$ & O०० \\
\hline 1019 & Alt & 91 & 4,46 & $-8,007$ & ,000 & M36 & Alt & 91 & 4,55 & & , 000 \\
\hline M10 & Üst & 91 & 2,84 & 10942 & 000 & M37 & Üst & 91 & 2,46 & $-18,249$ & 000 \\
\hline MIO & Alt & 91 & 4,69 & $-10,942$ & , 000 & M37 & Alt & 91 & 4,78 & & , 000 \\
\hline M11 & Üst & 91 & 3,54 & 7547 & ( & 438 & Üst & 91 & 2,21 & 15161 & , 000 \\
\hline MH & Alt & 91 & 4,64 & $-7,547$ &, 000 & 10138 & Alt & 91 & 4,52 & $-15,161$ & \\
\hline M12 & Üst & 91 & 2,51 & -13380 &, 000 & M39 & Üst & 91 & 2,60 & -13434 & 000 \\
\hline $\mathrm{MI1}$ & Alt & 91 & 4,62 & $-13,380$ & & 10139 & Alt & 91 & 4,60 & $-15,434$ & ,000 \\
\hline M13 & Üst & 91 & 3,03 & 11719 & 000 & M40 & Üst & 91 & 2,20 & 11091 & $0 \cap 0$ \\
\hline 10113 & Alt & 91 & 4,80 & $-11,119$ & , 000 & 10140 & Alt & 91 & 4,13 & $-11,091$ &, 000 \\
\hline M14 & Üst & 91 & 2,40 & 11245 & 000 & $M 41$ & Üst & 91 & 2,73 & 11586 & 000 \\
\hline M14 & Alt & 91 & 4,25 & $-11,245$ & ,000 & M41 & Alt & 91 & 4,60 & $-11,586$ & , 000 \\
\hline$M 15$ & Üst & 91 & 2,56 & 14104 & 000 & M42 & Üst & 91 & 2,46 & 16797 & , 000 \\
\hline 10110 & Alt & 91 & 4,71 & $-14,104$ &, 000 & 10142 & Alt & 91 & 4,73 & $-10,191$ & \\
\hline M16 & Üst & 91 & 2,68 & $-13,992$ & 000 & M43 & Üst & 91 & 2,66 & $-7,287$ & 000 \\
\hline 1016 & Alt & 91 & 4,71 & & , & $1 \mathrm{~N} 143$ & Alt & 91 & 4,02 & &, 000 \\
\hline 917 & Üst & 91 & 2,90 & $-9,815$ & ,000 & M44 & Üst & 91 & 2,58 & $-13,005$ & 000 \\
\hline 10117 & Alt & 91 & 4,44 & & & 10144 & Alt & 91 & 4,62 & & ,000 \\
\hline M18 & Üst & 91 & 2,82 & $-12,982$ & 000 & M45 & Üst & 91 & 2,80 & $-7,123$ & 000 \\
\hline M18 & Alt & 91 & 4,76 & & ,000 & 1)15 & Alt & 91 & 4,25 & & ,000 \\
\hline M10 & Üst & 91 & 2,95 & $-12,832$ & 000 & $M 46$ & Üst & 91 & 2,51 & $-9,408$ & , 000 \\
\hline 1019 & Alt & 91 & 4,77 & & , 000 & 10146 & Alt & 91 & 4,20 & & \\
\hline Мว० & Üst & 91 & 2,58 & $-14,979$ & 000 & M47 & Üst & 91 & 2,92 & $-9,204$ & 000 \\
\hline N120 & Alt & 91 & 4,76 & & , 000 & V14/ & Alt & 91 & 4,58 & & ,000 \\
\hline M21 & Üst & 91 & 2,60 & $-14,055$ & 000 & M48 & Üst & 91 & 2,42 & $-14,945$ & 000 \\
\hline & Alt & 91 & 4,73 & & ,000 & M18 & Alt & 91 & 4,63 & & , 000 \\
\hline М२? & Üst & 91 & 2,48 & $-15,905$ & 000 & M49 & Üst & 91 & 2,35 & $-15,299$ & 000 \\
\hline M22 & Alt & 91 & 4,81 & & , 000 & M49 & Alt & 91 & 4,71 & & , 000 \\
\hline 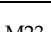 & Üst & 91 & 2,37 & $-15,373$ & 000 & 450 & Üst & 91 & 2,34 & $-15,208$ & , 000 \\
\hline 10123 & Alt & 91 & 4,67 & & & 10150 & Alt & 91 & 4,61 & & \\
\hline 924 & Üst & 91 & 2,44 & $-18,213$ & ( & M51 & Üst & 91 & 2,88 & $-7,769$ & 000 \\
\hline N24 & Alt & 91 & 4,86 & & ,000 & MbI & Alt & 91 & 4,29 & & , 000 \\
\hline M25 & Üst & 91 & 3,04 & $-12,097$ & 000 & M52 & Üst & 91 & 3,04 & $-6,540$ & 000 \\
\hline M25 & Alt & 91 & 4,79 & & ,000 & $\mathrm{M} 52$ & Alt & 91 & 4,23 & & , 000 \\
\hline M२ & Üst & 91 & 2,51 & $-15,783$ & ( & 452 & Üst & 91 & 2,55 & 94 & \\
\hline M26 & Alt & 91 & 4,79 & & ,000 & Mb3 & Alt & 91 & 4,45 & $-10,944$ & , 000 \\
\hline Mר7 & $\ddot{\text { Üst }}$ & 91 & 2,88 & 2800 & 000 & & & & & & \\
\hline $\mathrm{M} 27$ & Alt & 91 & 4,82 & $-12,809$ & & & & & & & \\
\hline
\end{tabular}


Tablo 3 madde ortalamaları için t-testi sonuçlarına göre ölçeğin tüm maddeleri için alt ve üst grup arasında istatistiksel olarak anlamlı bir fark olduğunu göstermektedir $(p<, 05)$. Dolayısıyla bu sonuca dayanarak hiçbir madde ölçekten çıkarılmamıştır.

Madde-Toplam Puan Korelasyonu: Ölçekteki 53 maddenin her birinin ayırt ediciliği diğer ifadeyle madde toplam korelasyonu incelenmiştir. Maddelerin puanlarının sıralanmış haliyle ölçeğin toplam puanı ile ilgili ilişki Tablo 4' de verilmiştir.

Tablo 4. Ölçeğin Madde Analizi Sonuçları

\begin{tabular}{llllll}
\hline No & $\begin{array}{l}\text { Madde Toplam } \\
\text { Korelasyonu }\end{array}$ & No & $\begin{array}{l}\text { Madde Toplam } \\
\text { Korelasyonu }\end{array}$ & No & $\begin{array}{l}\text { Madde Toplam } \\
\text { Korelasyonu }\end{array}$ \\
\hline M1 &, 833 & M 19 &, 727 & M37 &, 847 \\
\hline M2 &, 837 & M20 &, 787 & M38 &, 804 \\
\hline M3 &, 799 & M21 &, 773 & M39 &, 759 \\
\hline M4 &, 714 & M22 &, 812 & M40 &, 717 \\
\hline M5 &, 780 & M23 &, 801 & M41 &, 716 \\
\hline M6 &, 743 & M24 &, 845 & M42 &, 797 \\
\hline M7 &, 582 & M25 &, 726 & M43 &, 543 \\
\hline M9 &, 722 & M26 &, 780 & M44 &, 756 \\
\hline M10 &, 599 & M27 &, 719 & M45 &, 509 \\
\hline M11 &, 681 & M28 &, 789 & M46 &, 658 \\
\hline M12 &, 446 & M29 &, 701 & M47 &, 563 \\
\hline M13 &, 745 & M30 &, 750 & M48 &, 814 \\
\hline M14 &, 722 & M31 &, 771 & M49 &, 820 \\
\hline M15 &, 697 & M32 &, 725 & M50 &, 812 \\
\hline M16 &, 787 & M33 &, 790 & M51 &, 557 \\
\hline M17 &, 755 & M34 &, 659 & M52 &, 495 \\
\hline M18 &, 628 & M35 &, 752 & M53 &, 670 \\
\hline &, 753 & M36 &, 761 & & \\
\hline
\end{tabular}

Maddelerin puan dizisi ile ölçeğin toplam puanı arasındaki ilişkileri incelendiğinde her bir madde için değerlerin , 6 'dan büyük ve pozitif yönlü olduğu belirlenmiştir. Gerçekleştirilen madde analizi ile madde-toplam korelasyonları baz alınarak, ölçek maddelerinin güvenirlikleri tespit edilmiştir. Korelasyon katsayısı $\mathrm{r} \geq .40$ için çok iyi bir madde ve $.30 \leq \mathrm{r} \leq .39$ için iyi derecede bir maddedir (Büyüköztürk, 2005). Tablo 4 incelendiğinde araştırmada geliştirilen ölçeğin $t$ değerleri anlamlı olup, tüm katsayılar .60-.766 arasında değişmektedir. Bu nedenle de ölçekten herhangi bir madde çıkarılmamıştır. 


\section{Geçerlik Hesaplama Aşaması}

Gerçekleştirilen çalışmada bu kademede ölçeğin yapı geçerliği analiz edilmiştir. Faktör Analizinin yapılabilmesi için başlıca koşul Kaiser-Mayer-Olkin (KMO) ve Barlett testi yapılmış ve sonuçları Tablo 5'te gösterilmiştir.

Tablo 5.Ölçeğin Kaiser-Mayer-Olkin (KMO) Örneklem Ölçüm ve Barlett's Test Sonuçlarn

\begin{tabular}{lll}
\hline Kaiser-Meyer-Olkin & &, 956 \\
\hline \multirow{3}{*}{ Bartlett's Test } & Ki-Kare & 8970,781 \\
\cline { 2 - 3 } & sd & 1378 \\
\hline & $\mathrm{p}$ &, 000 \\
\hline
\end{tabular}

${ }^{*} \mathrm{p}<001$

Kaiser-Mayer-Olkin (KMO), örneklemin ve ölçek maddeleri arasındaki ilişkinin uyumu ile ilgili bir değerdir. Kaiser-Mayer-Olkin (KMO) sayısının .60 'tan büyük olması kabul edilebilir olarak ifade edilebilir olarak ifade edilmektedir. Kaiser-Mayer-Olkin (KMO) değerlerinin büyük çıması, Barlett değerlerinin de büyük çıkmasını sağlayacaktır. Böylece ikisinin de büyük olması faktör analizi için uygulanabilirliği ve maddeler arasındaki ilişki değerlerinin büyük olduğunu ortaya koyacaktır (Şeker, Deniz ve Görgen, 2004). Ölçeğin Kaiser-Mayer-Olkin (KMO) değerinin .956, Barlett testi anlamlllık değerinin $p<.05$ olduğu belirlenmiştir. Bu değer faktör analizi için uygulanabilirliğin ve maddeler arasındaki ilişkinin anlamlı olduğunu ifade etmektedir.

Yapılan faktör analizi sonucunda tutum ölçeğinde yer alan maddelerden ortak faktör varyans değerleri düşük olmadığı gözlenmektedir. Aşağıdaki Tablo 6'da tutum ölçeğinde yer alan maddelerin ortak faktör varyans değerleri verilmiştir. 
Tablo 6. Ölçeğin Maddelerin Ortak Faktör Varyans Değerleri

\begin{tabular}{|c|c|c|c|c|c|c|c|c|c|c|c|}
\hline$\frac{\frac{ \pm}{\tilde{J}}}{\frac{\pi}{\pi}}$ & 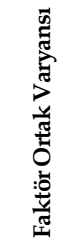 & $\begin{array}{l}\frac{\vec{v}}{d} \\
\frac{\pi}{0} \\
\frac{\pi}{2}\end{array}$ & 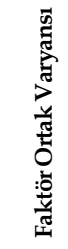 & 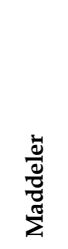 & 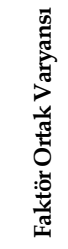 & 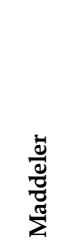 & 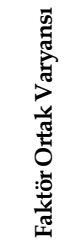 & 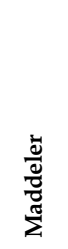 & 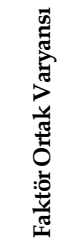 & $\frac{\frac{ \pm}{d}}{\frac{\tilde{d}}{\pi}}$ & 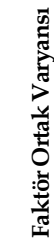 \\
\hline M1 & .809 & M10 & .590 & M 19 & .736 & M28 & .726 & M37 & .776 & M46 & .735 \\
\hline M2 & .831 & M11 & .722 & M20 & .742 & M29 & .634 & M38 & .787 & M47 & .301 \\
\hline M3 & .728 & M12 & .685 & M21 & .715 & M30 & .706 & M39 & .712 & M 48 & .741 \\
\hline M4 & .719 & M13 & .650 & M22 & .741 & M31 & .748 & M40 & .750 & M 49 & .726 \\
\hline M5 & .747 & M14 & .623 & M23 & .717 & M32 & .650 & M41 & .634 & M50 & .777 \\
\hline M6 & .697 & M15 & .695 & M24 & .768 & M33 & .749 & M 42 & .710 & M51 & .292 \\
\hline M7 & .510 & M16 & .667 & M25 & .634 & M34 & .654 & M 43 & .292 & M52 & .677 \\
\hline M8 & .592 & M17 & .711 & M26 & .717 & M35 & .806 & M 44 & .686 & M53 & .608 \\
\hline M9 & .513 & M18 & .760 & M27 & .726 & M36 & .680 & M45 & .712 & & \\
\hline
\end{tabular}

Faktör analizinde büyük öneme sahip olan faktör yük değerleridir. Büyüköztürk (2005), maddelerin faktör yük değerleri .45 ya da daha büyük olması iyi bir değeri gösterdiğ i ifade edilmektedir. Bu nedenle 43., 47. ve 51. maddeler faktör yük değerleri 45 değerinden küçük olmalarından dolayı ölçekten çıkarılmışlardır. Böylece ölçekte yer alan maddelerin ortak faktör varyanslarının .510-.831 arasında değiştiği belirlenmiştir. Bu duruma göre, maddelerin ortak faktör varyanslarının yüksek değerde olduğu ifade edilebilir. Ayrıca Temel bileşenler matriksi (Component Matrix) incelendiğinde 11., 45. ve 52. maddelerin binişik maddeler olduğu belirlenmiştir. Dolaysıyla bu maddeler ölçekten çıkarılmıştır. Böylece ölçekteki 47 maddenin toplam varyans değerleri incelendiğinde analize alınan maddelerin tek faktör altında toplanması durumunda açıkladıkları varyansın \%56.753 olduğu belirlenmiştir. Öz değer çizgi grafiğine bakıldığında (Grafik 1) öz değer çizgisinde birinci faktörden sonra yüksek ivmeli bir düşüş belirlenmiştir. Bu sonuç, ölçeğin bir faktöre sahip olacağını ortaya çıkarmaktadır. 


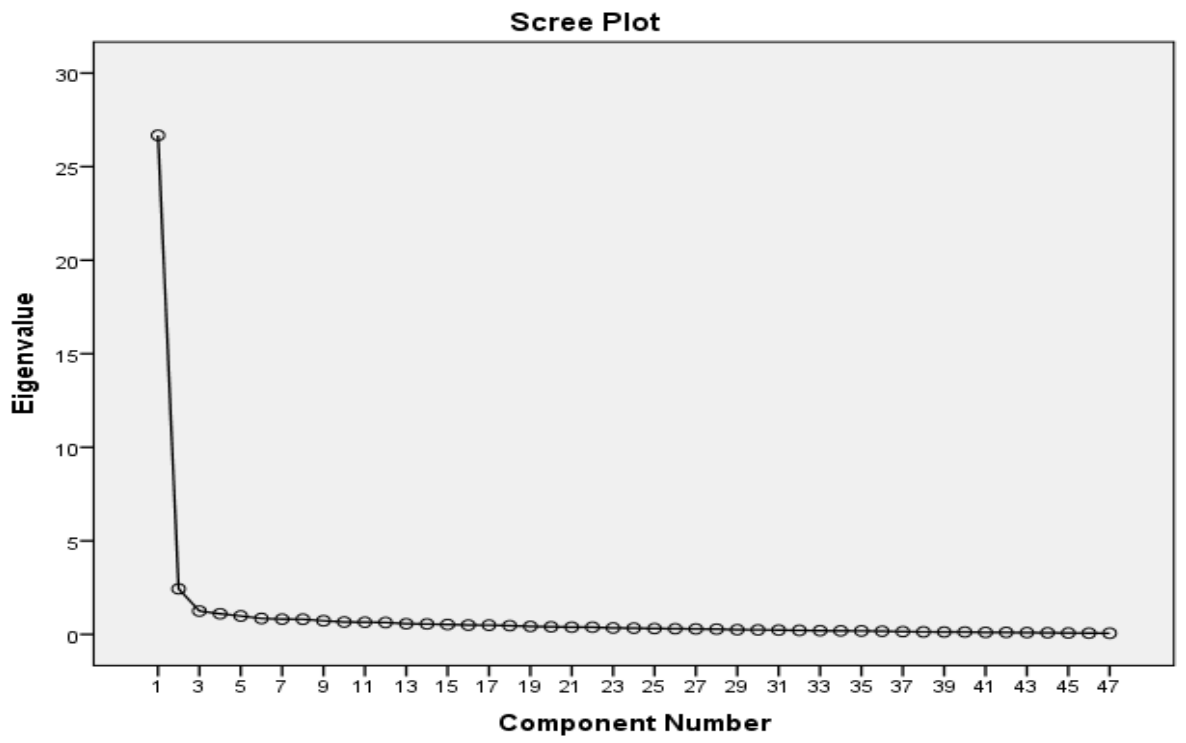

Grafik 1. Ölçeğin Maddelerin Ortak Faktör Varyans Değerleri

Tek faktörlü ölçeklerde açıklanan varyansın \%30 ve üzerinde olması ölçek tek faktörlü olması için yeterli görülmektedir (Büyüköztürk, 2005) ölçeği oluşturan tek faktörün açıladığı toplam varyans \% 56,75'dür. Çalışmanın güvenirlik analizi yapılarak güvenlik katsayısı Cronbach Alfa $\alpha=.93$ olarak belirlenmiştir.

Açımlayıcı faktör analizi sonucunda belirlenen bir faktörün doğruluğunu test etmek için doğrulayıcı faktör analizi yapılmıştır. Doğrulayıcı faktör analizi sonucunda önerilen modifikasyon indeksleri incelenmiş ve ki-kare istatistiğini en çok düşüren "e1 ve e2", "e4 ve e5" maddeleri arasında gerekli modifikasyonlar yapıldıktan analiz tekrar edilmiştir. Kalan 47 maddeye dair analiz sonucu ortaya çlkan model Şekil 3'te gösterilmiştir.

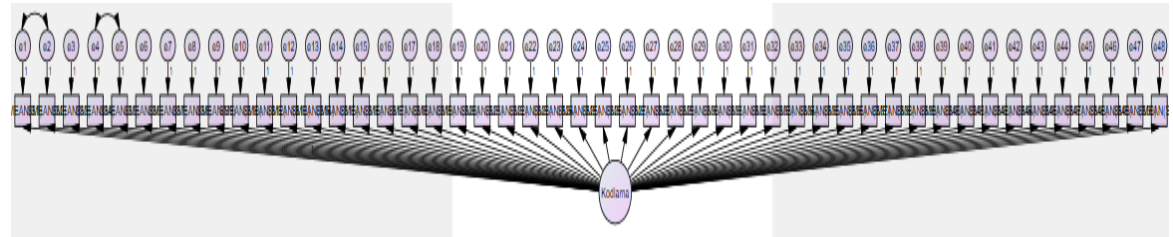

Şekil 3. Ortaokul öğrencilerinin kodlamaya karşı tutumların ölçmek için geliştirilen ölçeğin Doğrulayıcı Faktör Analiz Modeli (Standartlaştırılmış Değerler) 
Ölçeğin tek faktörlü yapısı ile ilgili uyum indekslerine bakılmıştır ve analiz sonucunda elde edilen modelin uyum indeksleri Tablo 7'de verilmiştir.

Tablo 7. DFA Sonucunda Elde Edilen Uyum Değerleri .

\begin{tabular}{lllllll}
\hline $\boldsymbol{\chi} \mathbf{2}$ & sd & $\boldsymbol{\chi} \mathbf{2} / \mathbf{s d}$ & RMSEA & GFI & CFI & IFI \\
\hline 3359,735 & 1079 & 3,117 &, 079 &, 590 &, 745 &, 747 \\
\hline
\end{tabular}

Tablo 7 incelendiğinde, doğrulayıcı faktör analizi (DFA) sonucunda elde edilen Ki-kare ve serbestlik derecesi değerlerinin $\chi 2=3359,735$ ( $\mathrm{sd}=1079$, $\mathrm{p}<.01$ ) olduğu görülmektedir. DFA sonucu, $\chi 2 / \mathrm{sd}=3,117$ oranı elde edilmiştir. $\mathrm{Bu}$ oran seçilen örneklemden elde edilmekte olup, değerin 3 'ün altında çıkması mükemmel uyumu göstermektedir (Sümer, 2000). Bu oranın 5'in altında çıkması uyumun iyi olduğu anlamı taşımaktadır (Karagöz, 2017). Bu araştırmada elde edilen DFA sonucu model ile veri arasındaki uyumun iyi olduğunu gösterdiği söylenebilir.

DFA'da en yaygın kullanılan uyum eksikliği indekslerinden birisinin RMSEA (rootmeansquareerror of approximation) olduğu söylenebilir (Durkan, 2017). RMSEA sayısının .05'den küçük oluşu model uygunluğu seviyesinin iyi derecede olmasını, .08 sayısının da kabul edilebilir değere sahip olduğunu göstermektedir (Schermelleh-Engel, Moosbrugger ve Muller, 2003; Kumlu, Kumlu ve Yürük, 2017). Çalışmamızda RMSEA değeri .079 olarak belirlenmiştir. Bu değer de Kabul edilebilir düzeydedir.

Doğrulayıcı Faktör Analizi Açımlayıcı Faktör Analizi ile ortaya çıarılan faktörlerin, hipotezle belirlenmiş faktör yapısına uygunluğunu test etmek için kullanılmaktadır (Aytaç ve Öngen, 2012). Bu bağlamda, ortaokul öğrencilerinin kodlamaya karşı tutum ölçeğinin tek faktörden oluştuğu onaylanmıştır. Açımlayıcı ve doğrulayıcı faktör analizleri sonucunda ölçekte 47 madde kalmıştır.

\section{Tartışma ve Sonuç}

Ortaokul öğrencilerinin kodlayamaya ilişkin tutumlarını ölçen geçerli ve güvenilir bir ölçme aracının geliştirilmesini amaçlayan bu çalışmada başlangıçta 53 maddeden oluşturulan taslak tutum ölçeği 675 öğrenciye uygulanmış ve 47 madde içeren bir ölçek geliştirilmiştir. Kırk yedi maddeye uygulanan KMO değeri .956 ve Bartlett testi anlamlılık değeri ise $\mathrm{p}<.05$ dir. Bu sayı "çok 
iyi" olarak nitelendirilmektedir (Field, 2002). Sonuç olarak, veriler üzerine uygulanan faktör analizinin güvenilir değerler ortaya koyduğu ifade edilebilir. Ölçeğin maddelerinin toplam varyans değerlerine bakıldığında analiz edilen 47 maddenin tek faktörde topland ı̆̆ı, bu faktörün de varyansı \%56.75'ni açıladığı belirlenmiştir. Öz değer çizgisinde birinci faktörden sonra yüksek ivmeli bir düşüş görülmüştür. Bu da, ölçeğin bir faktöre sahip olabileceğini göstermektedir.

Ölçekte yer alan maddelerin faktör yük değerlerinin .470 ve üzerinde olduğu görülmüştür. Bu değer, Büyüköztürk (2005) 'ün bir maddenin ölçme aracına alınabilmesi için öngördüğü faktör yükü ölçütünü karşılamaktadır. Ölçeğin güvenirliği ile ilgili olarak Cronbach Alfa güvenirlik katsayısı .93 olarak bulunmuştur. Bu değer 1'e yakındır. Karasar (2012)'a göre güvenirlik katsayısının 1'e yaklaşması ölçüm aracı için iyi ve yeterlidir. Üst grup alt grup arasında anlamlı fark olduğunu gösteren analizler, t değerlerinin anlamlılığ ve madde toplam korelasyonlarının büyük olması ölçeğin geçerliliğini kanıtlamaktadır.

Doğrulayıcı faktör analizinin sonuçlarına göre elde edilen $\chi 2$ değeri, $\chi 2 / \mathrm{df}$, RMSEA uyum indekslerine göre ölçeğe ilişkin tek faktörlü yapının kabul edilebilir uyum düzeyine sahip olduğunu göstermektedir (Gökkuş, Kuru ve Şimşek, 2016). Tek faktörlü 47 maddeden oluşan bu yapının güvenirlik katsayısının (Cronbach alpha) 93 olduğu görülmüştür. Geçerlik ve güvenirlik çalışmalarından elde edilen bulgular geliştirilen ölçeğin kodlamaya yönelik tutumu ölçmede güvenle kullanılabileceğini göstermektedir. $\mathrm{Bu}$ alanda Keçeci, Alan ve Zengin (2016) eğitsel bilgisayar oyunları destekli kodlama öğrenimine yönelik tutumları belirlemek için bir ölçek geliştirilmiş olsa da kodlama gelecekte birçok ders kapsamında kullanılacağı düşünülmektedir. Bu bağlamda bu ölçek, Türkçe geliştirilmiş kodlamaya karşı tutumu ölçen öncelikli ölçeklerden birisidir. Bu ölçeğin kullanılması ile elde edilen verilere bağlı olarak öğrencilerin kodlamaya karşı tutumlarını belirlemeye yönelik çalışmalar yapılabilir. 


\title{
EXTENDED ABSTRACT
}

\section{Students' Attitudes Towards Coding: A Study of Scale Development}

\author{
$*$ \\ Mustafa Serkan Abdüsselam - Mustafa Uzoğlu \\ Giresun University
}

Program and coding are not new concepts in the student world. However, with the development of technology from day to day, the meanings of these concepts have expanded. For the student, the program can be considered as a directive in which the student organizes the activities and lists the steps that should be followed daily. However, in the computer literature, the program covers the entire structure that takes action by the processor following the steps envisaged by the developed algorithm for the solution of the problem. The generated structure can be defined as programming.

Students express the answers they give to the exam questions during the examination as an act of marking the answer sheet. In the computer language, coding refers to code blocks or code texts that are specific to that programming language in the framework of the steps (algorithm) designed to solve a problem. Programming, therefore, requires a variety of cognitive skills, including coding. Coding must be performed to create the program.

When the history of programming teaching is examined, it is seen that the usage of the Logo programming language has started in the 1960s. Increasing interest in programming learning from day to day led to the organization of organizations such as code.org and rapid expansion of programming tools such as Scratch. Since 2012, Turkey has begun to teach these contents with the Information Technology and Software course in secondary schools. Scratch based on the block encoding provided by the easy interface to facilitate coding. Since the ease of coding increases the motivation and interest of the students in the classroom, the use of Scratch has become widespread in this course. Recent research shows that teachers should be familiar with, even dominate, coding and programming within the framework of block-based coding and STEM training. 
In summary, programming can be said, in the teaching of coding, in particular, to be more advantageous using software based on block coding, to facilitate teaching, and indirectly have a positive effect on students' development of different thinking skills. In this effect, students' views on coding, whether they like it or not, and their attitudes are more important. Student attitudes and cognitive are important because what they will do in practice, how they will be physically and mentally affected by the learning process and the gains they will have in the future will guide the prediction of their coding achievements. Since it is known that the attitude towards learning subject or situation affects the performance of the student, it is important to determine the attitudes of the students related to block coding in the content of Information Technology and Software course, and therefore it is necessary to develop the coding attitude scale. Although the subject-related scale has recently been developed for educational computer games, it is envisaged that a coding tool is needed to measure students' attitudes towards coding, considering that coding skills are particularly important in STEM education. In this study, it is aimed to improve the attitude towards the coding scale to meet this need and to eliminate this deficiency in the literature.

In this screening study, it was aimed to develop an attitude scale that can show the attitudes of secondary school students towards coding validly and reliably. Likert type attitude scale model, which is widely used in attitude scales, was adopted in the study. The scale of attitude towards coding was developed for 5th, 6th, 7th and 8th-grade students who received coding education within the scope of information technologies and computer courses. A total of 675 students from different classes at the secondary level provided data to the study. The stratified aim-based sampling method was used to determine the participants. Data were collected in two stages during the scale development process. In the first stage, the data collected from 338 students in the 5 th, 6th, 7th and 8th-grade (study group 1 ) were used to determine the factor structure of the scale, and the data collected from 337 students (study group 2) in the second round were used to verify the factor structure obtained.

Initially, a draft scale of scale consisting of 53 items was applied to 675 students and a final scale consisting of 47 items was created. The KMO value applied to 47 items was .956 and the Bartlett test was $\mathrm{p}<.05$. This value cor- 
responds to the classification of "very good". Thus, it can be said that the factor analysis of these data gives reliable results. When the total variance values of the items in the scale were analyzed, it was seen that 47 items gathered under one factor and the variance explained by this factor on the scale was $56.75 \%$. In the scree plot drawn according to the core value, a decrease with high acceleration after the first factor was detected in the eigenvalue line. This showed that the scale could have a factor in general.

Factor load values of the items in the scale were found to be .470 and above. This value satisfies the factor load criterion that a substance requires to be taken into the measuring instrument. The Cronbach Alpha reliability coefficient for the reliability of the scale was found to be .93 . This value is close to 1 . The reliability coefficient approaching 1 is good and sufficient for the measurement tool. As a result of the analysis, a significant difference between the upper group and the subgroup, the significance of $t$ values and the high total item correlations prove the validity of the scale.

According to the results of confirmatory factor analysis, $\chi 2$ value, concerning $\chi 2 / \mathrm{df}$, RMSEA compliance indices, shows that the single factor structure related to the scale has an acceptable compliance level. The reliability coefficient (Cronbach alpha) of this structure, consisting of 47 items with a single factor, was found to be .93 .

Findings from validity and reliability studies show that the developed scale can be used safely to measure attitudes towards coding. This scale is the first scale study to measure the attitude towards Turkish developed coding. Depending on the data obtained by using this scale, studies can be conducted to determine the students' attitudes towards coding.

\section{Kaynakça / References}

Aytaç, M., ve Öngen, B. (2012). Doğrulayıcı faktör analizi ile yeni çevresel paradigma ölçeğinin yapı geçerliliğinin incelenmesi. İstatistikçiler Dergisi: İstatistik ve Aktüerya, 5(1), 14-22.

Balanskat, A., ve Engelhardt, K. (2014). Computing our future: Computer programming and coding-Priorities, school curricula and initiatives across Europe. European Schoolnet: Belgium.

Balcı, A. (2010). Sosyal bilimlerde araştırma yöntem, teknik ve ilkeleri. PegemA Yaynnevi: Ankara. 
Baratè, A., Ludovico, L. A., ve Mangione, G. R. (2016). A web framework to develop computational thinking through music coding. Proceedings of the 2nd International Conference on New Music Concepts (ICNMC 2016) içinde (s. 157-167), ABEditore.

Barendsen, E., Mannila, L., Demo, B., Grgurina, N., Izu, C., Mirolo, C., ... , Stupurienè, G. (2015, July). Concepts in K-9 computer science education. Proceedings of the 2015 ITiCSE on working group reports içinde (s. 85-116). ACM.

Begosso, L. C., ve da Silva, P. R. (2013, October). Teaching computer programming: A practical review. 2013 IEEE Frontiers in Education Conference (FIE) içinde (s. 508-510). IEEE.

Bindak, R. (2005). Tutum ölçeklerine madde seçmede kullanılan tekniklerin karşılaştrrılması. İnönü Üniversitesi Eğitim Fakültesi Dergisi. 6 (10), 17-26.

Bozdoğan, A. E. (2014). Bir küresel ısınma tutum ölçeği geliştirilmesi. Erzincan Üniversitesi Fen Bilimleri Enstitüsü Dergisi, 2(1), 35-50.

Bozdoğan, A. E. (2016). Development of self-efficacy belief scale for planning and organizing educational trips to out of school settings. Journal of Theoretical Educational Science/Kuramsal Eğitimbilim Dergisi, 9(1), 111-129.

Bozdoğan, A. E., ve Öztürk, Ç. (2008). Coğrafya ile ilişkili fen konularının öğretimine yönelik öz-yeterlilik inanç ölçeğinin geliştirilmesi. Necatibey Eğitim Fakültesi Elektronik Fen ve Matematik Eğitimi Dergisi (EFMED), 2(2), 66-81.

Bozdoğan, A.E. ve Uzoğlu, M. (2012(. The development of a scale of attitudes toward tablet pc. Mevlana International Journal of Education (MIJE), 2(2), 85-95.

Brennan, K., ve Resnick, M. (2013, March). Stories from the scratch community: connecting with ideas, interests, and people. In Proceeding of the 44th ACM technical symposium on Computer science education içinde (s. 463-464). ACM.

Brown, Q., Mongan, W., Kusic, D., Garbarine, E., Fromm, E., ve Fontecchio, A. (2008, June). Computer aided instruction as a vehicle for problem solving: Scratch boards in the middle years classroom. In ASEE Annual Conference and Exposition, Conference Proceedings içinde (s. 22-24).

Büyüköztürk (2005). Sosyal bilimler için veri analizi el kitabı (5. Baskl). PegemA Yayınc1lik: Ankara.

Çatlak, Ş., Tekdal, M., ve Baz, F. Ç. (2015). Scratch yazılımı ile programlama öğretiminin durumu: Bir doküman inceleme çalışması. Journal of Instructional Technologies ve Teacher Education, 4(3), 13-25.

Demir, A. G. Ö., ve Seferoğlu, S. S. (2017). Yeni kavramlar, farklı kullanımlar: bilgiişlemsel düşünmeyle ilgili bir değerlendirme. Eğitim teknolojileri okumalarn, 41, 468-483. 
Demirer, V., ve Nurcan, S. A. K. (2016). Programming education and new approaches around the world and in Turkey/Dünyada ve Türkiye'de programlama eğitimi ve yeni yaklaşımlar. Eğitimde Kuram ve Uygulama, 12(3), 521-546.

Demirer, V., ve Sak, N. (2015). Türkiye'de bilişim teknolojileri (BT) eğitimi ve BT öğretmenlerin değişen rolleri. Uluslararası Eğitim Bilimleri Dergisi, 2(5), 434-448.

Durkan, E. (2017). İlkokul dördüncü sinflarda görev yapan sını öğretmenlerinin Türkçe derslerinde öğrencilerinin üstbilişsel okuma stratejileri kullanmaların sağlayan uygulamalarının değerlendirilmesi: Giresun ili örneği. Yayınlanmamış yüksek lisans tezi. Giresun üniversitesi, Sosyal Bilimler Enstitüsü, İköğretim Ana Bilim Dalı, Giresun.

Eguchi, A. (2014, July). Robotics as a learning tool for educational transformation. Proceeding of 4th international workshop teaching robotics, teaching with robotics ve 5th international conference robotics in education Padova (Italy).

Field, A. (2002). Discovering Statistics Using SPSS. Sage Publications Ltd., UK: London.

Fraenkel, J. R., ve Wallen, N. E. (2003). How to design and evaluate research in education (5 $5^{\text {th }}$ Edition). New York: Mac Graw Hill, Inc

Fritz, R. (2008). The power of a positive attitude: Discovering the key to success. AMACOM Div : American Mgmt Assn.

Gökkuş, İ., Kuru, E., ve Şimşek, A. S. (2016). Kütüphaneye yönelik tutum ölçeği geçerlilik ve güvenirlik çalışması. The Journal of Academic Social Science Studies, 1(42), 465-465.

Guenaga, M., Menchaca, I., Garaizar, P., ve Eguíluz, A. (2017, October). Trastea. club, an initiative to develop computational thinking among young students. In Proceedings of the $5^{\text {th }}$ International Conference on Technological Ecosystems for Enhancing Multiculturality içinde (s. 10). ACM.

Howland, K., ve Good, J. (2015). Learning to communicate computationally with Flip: A bi-modal programming language for game creation. Computers ve Education, 80, 224-240.

Karagöz, Y. (2017). Spss ve Amos uygulamalı nitel-nicel karma bilimsel araştırma yöntemleri ve yayın etiği. Nobel Yayıncllk: İstanbul.

Karasar, N. (2012). Bilimsel araştırma yöntemi. Nobel Yayıncılık. Ankara.

Keçeci, G., Alan, B., ve Zengin, F. K. (2016). Eğitsel bilgisayar oyunları destekli kodlama öğrenimine yönelik tutum ölçeği: geçerlilik ve güvenirlik çalışmas1. Education Sciences, 11(3), 184-194.

Kind, P., Jones, K. ve Barmby, P. (2007). Developing attitudes towards science measures. International Journal of Science Education. 29 (7), 871-893. 
Kumlu, G.D., Kumlu, G. ve Yürük, N. (2017). Üniversite öğrencileri için fen metinlerini okumaya yönelik tutum ölçeğinin geliştirilmesi: Geçerlik ve Güvenirlik Çalışması. Kastamonu Ĕ̆itim Dergisi, 25 (1), 203-220.

Love, B., Winter, V., Corritore, C., ve Faimon, D. (2016, June). Creating an environment in which elementary educators can teach coding. Proceedings of the The 15th International Conference on Interaction Design and Children (s. 643-648). ACM.

Lye, S. Y., ve Koh, J. H. L. (2014). Review on teaching and learning of computational thinking through programming: What is next for K-12?. Computers in Human Behavior, 41, 51-61.

Moreno-León, J., Robles, G., ve Román-González, M. (2015). Dr. Scratch: Automatic analysis of scratch projects to assess and foster computational thinking. RED. Revista de Educación a Distancia, 46, 1-23.

Sayın, Z., ve Seferoğlu, S. S. (2016). Yeni bir 21. yüzyıl becerisi olarak kodlama eğitimi ve kodlamanın eğitim politikalarına etkisi. Akademik Bilişim Konferansı, 3-5.

Schermelleh-Engel, K., Moosbrugger, H., ve Müller, H. (2003). Evaluating the fit of structural equation models: Tests of significance and descriptive goodnessof-fit measures. Methods of psychological research online, 8(2), 23-74.

Seale, C., Gobo, G., Gubrium, J. F., ve Silverman, D. (2007). Qualitative research practice. London: Sage Publications.

Sebetci, Ö., ve Aksu, G. (2014). Öğrencilerin mantiksal ve analitik düşünme becerilerinin programlama dilleri başarısına etkisi. Journal of Educational Sciences ve practices, 13(25), 65-83.

Sümer, N. (2000). Yapısal eşitlik modelleri: Temel kavramlar ve örnek uygulamalar. Türk psikoloji yazlları, 3(6), 49-74.

Şeker, H. ve Gençdoğan, B. (2006). Psikolojide ve eğitimde ölçme aracı geliştirme. Nobel Yayınları, Ankara.

Şeker, H., Deniz, S., Görgen, İ. (2004). Öğretmen yeterlikleri ölçeği. Milli Eğitim Dergisi. $164,105-118$.

Taccle 3 Coding. (2019, Mar 11). Portal TACCLE 3 Coding. http://www.taccle3.eu/en/ adresinden erişilmiştir.

Taylor, M., Harlow, A., ve Forret, M. (2010). Using a computer programming environment and an interactive whiteboard to investigate some mathematical thinking. Procedia-Social and Behavioral Sciences, 8, 561-570.

Tyler, L.E. (1971). Tests and measurements. Englewood Cliffs. Prentice-Hall. N. J. 
Yağcl, M. (2018). A Study on Computational Thinking and High School Students' Computational Thinking Skill Levels, International Online Journal of Educational Sciences, 10(2), 81-96.

Yaşar E. (2014), Algoritma ve programlamaya giriş, 5. Baskı, Ekin Bakım ve Dağıtım: Bursa.

Yurdugül, H. (2005). Ölçek geliştirme çalışmalarında kapsam geçerliği için kapsam geçerlik indekslerinin kullanılması. XIV. Ulusal Eğitim Bilimleri Kongresi, 1, 771-774.

Yükseltürk E., Üçgül M. (2018) Blok Tabanlı programlama. Y. Gülbahar ve H. Karal (Ed.), Kuramdan Uygulamaya Programlama Öğretimi içinde (s. 273-296), Pegem Akademi: Ankara .

Yünkül, E , Durak, G , Çankaya, S, ve Mısırlı, Z . (2017). Scratch yazılımının öğrencilerin bilgisayarca düşünme becerilerine etkisi. Necatibey Eğitim Fakültesi Elektronik Fen ve Matematik Eğitimi Dergisi, 11 (2), 502-517.

\section{Kaynakça Bilgisi / Citation Information}

Abdüsselam, M.S. ve Uzoğlu, M. (2020). Öğrencilerin kodlamaya yönelik tutumları: Bir ölçek geliştirme çalışması. OPUS-Uluslararası Toplum Araştırmaları Dergisi, 16(Eğitim ve Toplum Özel Sayısı), 58185840. DOI: 10.26466/opus.802939 